\title{
Replies to Kaczor and Rodger
}

\section{Christopher M. Stratman ${ }^{1}$}

Received: 16 November 2020 / Accepted: 20 November 2020/Published online: 12 January 2021

(C) The Author(s), under exclusive licence to Springer Nature B.V. part of Springer Nature 2021

\begin{abstract}
In these replies, I shall respond to criticisms offered by Kaczor and Rodger to my article (Stratman 2020) titled "Ectogestation and the Problem of Abortion." In the process, I shall also try to bring into focus why the possibility of ectogestation will radically alter the shape of the abortion debate.
\end{abstract}

Keywords Ectogenesis $\cdot$ Ectogestation $\cdot$ Abortion $\cdot$ Personhood $\cdot$ Gestateling

\section{Replies to Kaczor}

Christopher Kaczor (2020) offers three criticisms of my article (Stratman 2020) titled: "Ectogestation and the Problem of Abortion." But Kaczor never directly objects to what I call the "Main Argument" for the claim that even if we assume that the fetus is not a person at any point during its gestation, there is no right to secure its death, once ectogestation becomes a reasonable alternative available to the pregnant woman.

First, Kaczor criticizes my claim that "if the fetus is a proper part of the pregnant woman's body, then, at least for late-term fetuses, the pregnant woman would have duplicate hearts, livers, genitalia, and so on" (Stratman 2020). According to Kaczor, one can give a better defense of this claim than what is offered in the article. But it is not clear whether Kaczor thinks that a better defense is required. I would say that this claim is relatively uncontroversial. But context is crucial. The claim is made while discussing the view that one has a right to the death of the fetus because it is their property. So, perhaps a more charitable reading of Kaczor's criticism would be that a better defense of the claim that "fetuses are not owned by their genetic parents" is required. But even on this interpretation, it is not clear that a better defense is required. Kaczor is silent on this point. At best, Kaczor is suggesting that there may be other

Christopher M. Stratman

cstratman@huskers.unl.edu; https://orcid.org/0000-0001-9122-1236

1 Department of Philosophy, University of Nebraska-Lincoln, 315 Louise Pound Hall, PO. Box 880321, Lincoln, NE 68588-0321, USA 
reasons to reject the claim that a fetus is not the property of the genetic parents. But this alone would not constitute a problem for the argument that I defend in the article.

Interestingly, the defense that Kaczor offers refers to the fetus as a "prenatal human being." This is problematic for multiple reasons. The term "human being" is morally loaded, and Kaczor assumes that a human being is importantly connected to the ethical concept of personhood. According to Kaczor, then, all human beings, including prenatal human beings, are persons who have right to life. But this begs the question. ${ }^{1}$ Kaczor could improve the defense by making it clear that the term "prenatal human being" does not presuppose that the fetus is a person with moral rights, but then the defense would lose its force. Moreover, it is not implausible to think that one could be a person but not a human being or that one could be a human being but not a person. ${ }^{2}$ Kaczor ignores this possibility. But for Kaczor's criticism to be taken seriously, this possibility needs to be eliminated.

Second, Kaczor describes the fetus in strictly biological terms. But Kaczor fails to mention that there are two distinct ways of understanding what is meant by the term "human being." As Warren (1984) showed the term "human being" could be construed genetically to refer to species membership or one might also use the term to refer to membership in the moral community (p. 110). Kaczor slides between these two senses of the term "prenatal human being." Thus, Kaczor's better defense is guilty of equivocation, and I take this to be sufficient to reject it as a good defense of the claim that fetuses are not owned by their genetic parents.

Kaczor also criticizes the claim that if there is no morally relevant difference between a fetus and a cryopreserved embryo, then biological parents might have a right to destroy the fetus that they helped to create. But, again, context is crucial. This claim is made while discussing the intuition that cryopreserved embryos are owned by the biological parents. But I assume that a fetus is not a person at any point during its gestation and argue that there is no right to the death of the fetus. Of course, one could insist that a fetus is a person at every stage during its development, including the embryonic stage. But the second premise of the argument I defend in the article would handle such a view. ${ }^{3}$ The whole point of the article is to demonstrate that, even if we assume that a fetus is not a person at any point during its gestation, there is no right to its death, once ectogestation is a safe and reasonable alternative available to the pregnant woman. So, unless Kaczor's accepts this assumption, this criticism simply is not pertinent.

Third, Kaczor criticizes my claim that it would be strange to think that an immoral action might entail some new moral right that biological parents possess. According to Kaczor, adultery is a case where an immoral action can "give rise" to a new right possessed by the biological parents. But to claim that $X$ gives rise to $Y$ is not the same as saying that $X$ entails $Y$, and it is the entailment claim that I find strange. But even if we ignore this issue, Kaczor never mentions any new moral rights entailed by adultery, only parental responsibilities are mentioned as possibily arising from adultry. But these are not the same thing. One might think that adultery can bring about new parental responsibilities, but where is the argument for the claim that adultery can entail a new moral right that the biological parents did not already have prior to the adulterous act?

\footnotetext{
${ }^{1}$ This is not a new objection. For a discussion of this point, see Warren (1984, p. 110).

${ }^{2}$ For a discussion of such a view, see, e.g., Warren (1984, pp. 110-113).

3 The second premise of the Main Argument says: "If the fetus is a person, then given the possibility of ectogestation, at least in most cases, a woman does not have the right to the death of the fetus, though she has the right to end her pregnancy."
} 
Is adultery even immoral? I would argue that it is not, and Kaczor never gives an argument for the claim that it is immoral. But let us ignore this point for a moment and simply grant, for sake of the argument that it is immoral. Notice that adultery qua physical act of sexual intercourse might entail that the biological parents have new responsibilities. But why should we think that such the physical act of sexual intercourse itself is immoral? Suppose that one is in an abusive and non-loving relationship (or marriage if you prefer), and they have sex with someone other than their partner. If the sexual act is consensual, then it is hard to see why it would count as immoral, even if it technically counts as adultery. What would make an act of sexual intercourse immoral is if it somehow harms one's partner, perhaps by the breaking of a promise or some other form of oath breaking. Thus, adultery qua breaking one's promise might be immoral. But notice that adultery qua breaking one's promise does not entail (or give rise to) the existence of a child and parental responsibilities. Only adultery qua physical act of sexual intercourse could plausibly entail the existence of a new child and parental responsibilities. Indeed, the physical act of sexual intercourse is neither necessary nor sufficient for the existence of a new child or parental responsibilities, though the biological process of fertilization is necessary. But it is not clear why we should think that the biological process of fertilization would be immoral.

A better case might be rape, insofar as it is a clear case of an immoral action, and it can entail (or give rise ) to the existence of a child. So, one could argue that rape could entail parental responsibilities. But, is it plausible to think that such parental responsibilities could ground a new parental right once a child exists? I would say no. Perhaps there are better cases, but it is not immediately obvious what they might be. And Kaczor never actually tells us what new parental rights would be entailed by an immoral action. Only parental responsibilities are mentioned.

\section{Reply to Rodger}

Daniel Rodger (2020) offers several thoughtful remarks, which, I believe, ultimately help to illustrate how ectogestation will transform the abortion debate. Though Rodger is skeptical, I think this is due to a mistaken understanding of the transformation that I believe will occur. I do not argue that the possibility of ectogestation will end the abortion debate or significantly reduce the practice of lethal abortions. And I never claim that there should be a blanket implementation of legal restrictions on lethal abortions, once ectogestation is a safe and reasonable alternative available to pregnant women. Rather, I argue that the possibility of ectogestation will radically transform the abortion debate by removing the problem of fetal personhood as morally relevant for the question whether a woman's right to express her bodily autonomy by terminating her pregnancy entails that she has a right to the death of the fetus. I take this to constitute a significant change in the abortion debate, not merely a minor effect that can be ignored.

Rodger suggests that the possibility of ectogestation will force us to consider the moral status of a "gestateling" instead of the moral status of a fetus. While I agree that the moral status of gestatelings raises philosophically interesting questions, I doubt that it will play a morally significant role in determining whether there is a right to the death of the fetus. This is because if we replace "fetus" with "gestateling," the argument I defend still goes through. And Rodger seems to recognize that even if there is no right 
to the death of the fetus, the possibility of ectogestation will probably not lead to significant changes of opinions or to new legal restrictions regarding the practice of lethal abortions. From a certain point of view, I would agree with this claim. The fact that there is no moral right to the death of the fetus does not automatically guarantee that there will be sweeping reforms of social practice and opinions regarding lethal abortions or that new legal restrictions should be implemented in order to modify a woman's behavior. I believe that it is an open question to what extent social and legal norms will change once the practice of ectogestation becomes mainstream. But this is consistent with the claim that the possibility of ectogestation will radically transform the abortion debate in the way mentioned above.

Indeed, this raises a novel question for the abortion debate. If there is no right to the death of the fetus, then how can we justify the legal practice of lethal abortions? I take the significance of this new question to be evidence of the fact that the possibility of ectogestation will radically transformation of the abortion debate, insofar as the debate will no longer be construed in terms of a conflict of rights. What is needed is an argument that purports to show that even if there is no right to the death of the fetus, once ectogestation is possible, there are still good reasons to justify why one should be legally permitted to secure the death of the fetus.

For instance, one might appeal to the current conditions of the foster care system and the probability that such conditions will not significantly improve in the future without radical social and cultural change. This may factor into a consequentialist calculation that would allow us to reasonably infer that one can be justified in choosing to obtain a lethal form of terminating their pregnancy. One might also argue that if the possibility of ectogestation means that we should implement significant legal restrictions regarding the practice of obtaining lethal abortions, then this would ultimately do more harm to society, insofar as it would foster and maintain systemic misogynistic behaviors and expectations. Perhaps these sorts of consequentialist reasons would count against implementing legal restrictions on lethal abortions, once ectogestation becomes possible. But notice that this would be true even in the absence of a fundamental "moral" right to the death of the fetus. These issues were not explored in the paper, but Rodger's criticisms suggest that they should be in subsequent work.

\section{References}

Kaczor, C. (2020). Fuller defenses and partial critiques: a discussion of "Ectogestation and the Problem of Abortion”. Philosophy \& Technology. Online. https://doi.org/10.1007/s13347-020-00437-0.

Rodger, D. (2020). Why ectogestation is unlikely to transform the abortion debate: a discussion of 'Ectogestation and the Problem of Abortion'. Philosophy and Technology. Online. https://doi.org/10. 1007/s13347-020-00436-1.

Stratman, C. (2020). Ectogestation and the problem of abortion. Philosophy and Technology. Online. https:// doi.org/10.1007/s13347-020-00427-2.

Warren, M. A. (1984). On the moral and legal status of abortion. In J. Feinberg (Ed.), The problem of abortion (pp. 102-119). Belmont: Wadsworth Publishing Company.

Publisher's Note Springer Nature remains neutral with regard to jurisdictional claims in published maps and institutional affiliations. 